\title{
Lesões do sistema urinário em 1.063 cães $^{1}$
}

\author{
Maria Andréia Inkelmann², Glaucia D. Kommers ${ }^{3 *}$, Maria Elisa Trost² ${ }^{2}$ Claudio S.L. \\ Barros $^{3}$, Rafael A. Fighera ${ }^{3}$, Luiz Francisco Irigoyen ${ }^{3}$ e Isadora P. Silveira ${ }^{4}$
}

\begin{abstract}
Inkelmann M.A., Kommers G.D., Trost M.E., Barros C.S.L., Fighera R.A., Irigoyen L.F. \& Silveira I.P. 2012. [Lesions of the urinary system in 1,063 dogs.] Lesões do sistema urinário em 1.063 cães. Pesquisa Veterinária Brasileira 32(8):761-771. Laboratório de Patologia Veterinária, Departamento de Patologia, Universidade Federal de Santa Maria, Camobi, Santa Maria, RS 97105-900, Brazil. E-mail: glaukommers@yahoo.com

The aim of this study was to determine the prevalence, epidemiology, clinical significance, and possible associated causes of the urinary system lesions in dogs necropsied between January 1999 and December 2010 at the Laboratório de Patologia Veterinária of the Universidade Federal de Santa Maria (LPV-UFSM). To accomplish this, the necropsy reports were analyzed retrospectively. In this time frame, 3,189 dogs were necropsied and about $30 \%$ had lesions in the urinary system. In most of the dogs $(79.1 \%)$, lesions were single and in about $21 \%$ they were multiple, totalizing 1,373 lesions. Out of them, 1,014 (73.8\%) were observed in the kidney and 359 (26.2\%) were in the lower urinary tract (LUT). One third of the lesions in the urinary system were causes of spontaneous death or reason for euthanasia (SD/EUTH) of the affected dogs. The other two third of the lesions were considered incidental findings. The main renal lesions diagnosed, in descending order of prevalence, were: tubulointerstitial nephritis, infarct, granulomatous nephritis (parasitary), glomerulonephritis, metastatic/multicentric neoplasms, pyelonephritis/pyelitis, and hydronephrosis. The main LUT lesions, in descending order of prevalence, were: cystitis, presence of viral inclusions bodies (morbillivirus), urolithiasis, urinary bladder dilatation, urinary bladder rupture (with uroperitoneum), and metastatic/multicentric neoplasms. Epidemiological aspects such as gender, breed, and age of affected dogs had expressive variations according to the type of lesion diagnosed. Uremia was observed in a significant number of cases of SD/EUTH and was mostly due to renal lesions.
\end{abstract}

INDEX TERMS: Lesions of the urinary tract, diseases of dogs, pathology.

RESUMO.- Com o objetivo de realizar um estudo abrangente das lesões do sistema urinário em cães e determinar a sua prevalência, epidemiologia, importância clínica e possíveis causas associadas, foram revisados os protocolos de necropsias de cães realizadas no período de janeiro

\footnotetext{
${ }^{1}$ Received on April 15, 2012.

Accepted for publication on May 2, 2012.

Part of the Doctor thesis of the first author.

${ }^{2}$ Programa de Pós-Graduação em Medicina Veterinária, área de concentração em Patologia Veterinária, Centro de Ciências Rurais (CCR), Universidade Federal de Santa Maria (UFSM), Camobi, Santa Maria, RS 97105900, Brazil.

${ }^{3}$ Departamento de Patologia, Centro de Ciências da Saúde, UFSM, Avenida Roraima 1000, Santa Maria, RS 97105-900. *Corrresponding author: glaukommers@yahoo.com

${ }^{4}$ Curso de Medicina Veterinária, CCR-UFSM, Santa Maria, RS. Bolsista PIBIC/CNPq/UFSM.
}

de 1999 a dezembro de 2010 no LPV-UFSM. Nesse período foram necropsiados 3.189 cães e destes, cerca de $30 \%$ apresentaram lesões no sistema urinário. Na maioria dos cães $(79,1 \%)$ foram observadas lesões únicas e em aproximadamente $21 \%$ havia lesões múltiplas no sistema urinário, totalizando 1.373 lesões. Destas, $1.014(73,8 \%)$ foram observadas no rim. No trato urinário inferior (TUI) foram diagnosticadas $359(26,2 \%)$ lesões. Um terço das lesões no sistema urinário dos cães necropsiados foram causa de morte espontânea ou razão para eutanásia (ME/EUT). As demais foram consideradas como achados incidentais. As principais lesões renais diagnosticadas, em ordem decrescente de prevalência, foram: nefrite túbulo-intersticial, infarto, nefrite granulomatosa (parasitária), glomerulonefrite, neoplasmas metastáticos/multicêntricos, pielonefrite/ pielite e hidronefrose. As principais lesões do TUI diagnosticadas, em ordem decrescente de prevalência, foram: cis- 
tite, presença de inclusões virais (morbilivírus), urolitíase, dilatação da bexiga, ruptura de bexiga (com uroperitônio) e neoplasmas metastáticos/multicêntricos. As características epidemiológicas como sexo, raça e idade dos cães afetados tiveram variações expressivas de acordo com o tipo de lesão diagnosticada. Uremia foi observada em um número significativo de casos de ME/EUT e foi principalmente secundária a lesões renais.

TERMOS DE INDEXAÇÃO: Lesões do trato urinário, doenças de cães, patologia.

\section{INTRODUÇÃO}

Lesões do sistema urinário são frequentemente observadas em cães durante a necropsia ou na avaliação histopatológica do rim ou dos segmentos (ureteres, bexiga e uretra) que compõem o trato urinário inferior (TUI). As lesões do trato urinário têm sido classificadas na literatura veterinária principalmente de acordo com sua distribuição e etiopatogênese (Maxie \& Newman 2007, Newman et al.
2007, Serakides 2010), associando-se a fatores clínico-epidemiológicos e às repercussões da ocorrência dessas lesões (Cowgill \& Elliott 2008, Lulich et al. 2008, Polzin et al. 2008). Várias delas são consideradas achados incidentais de necropsia (Maxie \& Newman 2007, Newman et al. 2007, Serakides 2010), porém podem ser a causa da morte ou razão para eutanásia nessa espécie animal, muitas vezes associadas à insuficiência renal aguda ou crônica (Fighera et al. 2008, Trapp et al. 2010, Fleming et al. 2011).

Considerando-se as diferenças regionais, principalmente ligadas à prevalência de determinadas etiologias/ doenças que acometem cães, o que repercute diretamente na prevalência de determinadas lesões do sistema urinário, tornam-se necessários estudos abrangentes que permitam estabelecer as principais lesões e suas associações dentro de um contexto diagnóstico.

Os objetivos deste estudo foram determinar a prevalência das lesões do sistema urinário em cães necropsiados num período de 12 anos, bem como sua distribuição anatômica, suas causas (quando estabelecidas), suas caracterís-

Quadro 1. Prevalência e epidemiologia das lesões renais em 1.063 cães necropsiados no Laboratório de Patologia Veterinária da Universidade Federal de Santa Maria (LPV-UFSM) de janeiro de 1999 a dezembro de 2010 (12 anos)

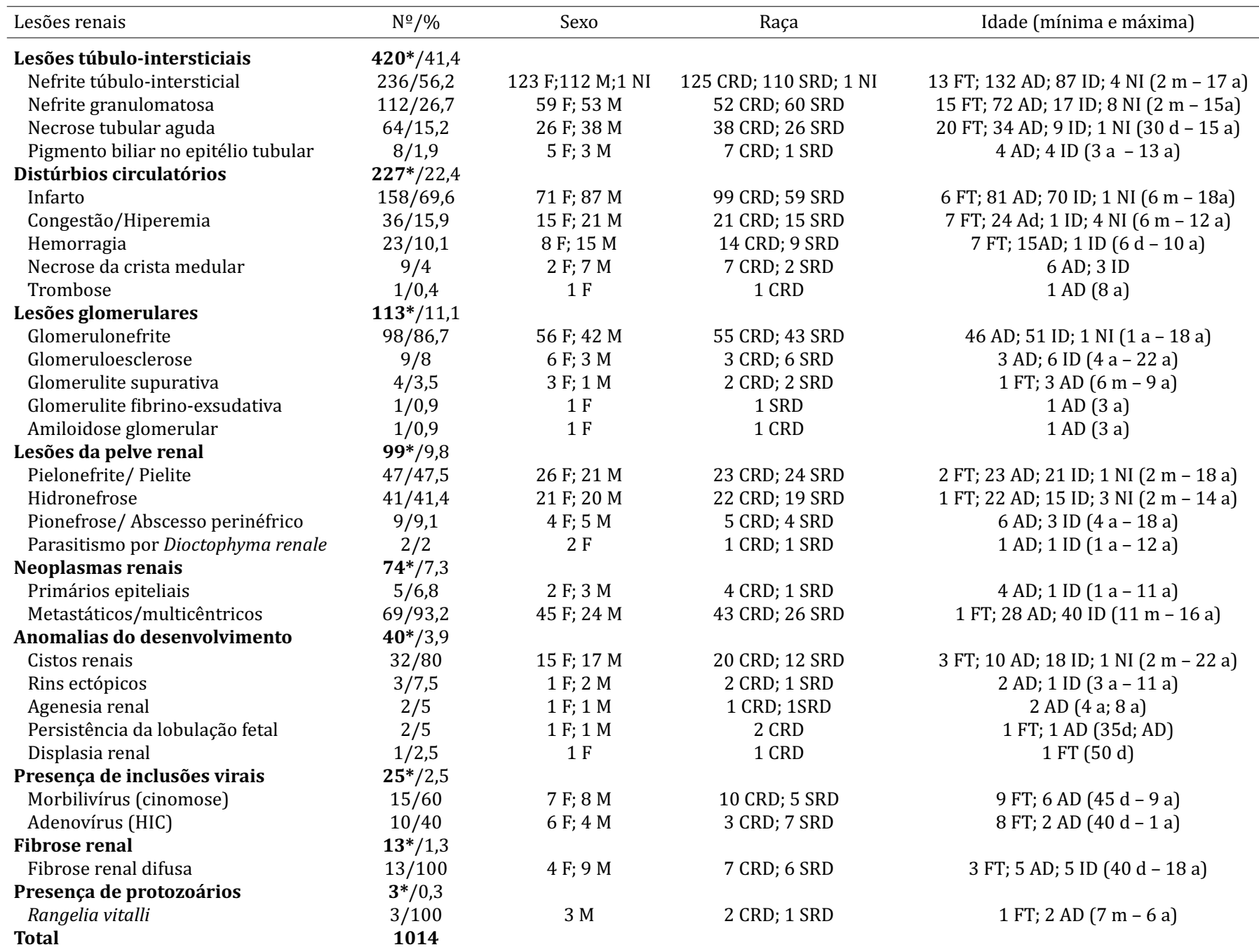

F = fêmeas; $\mathrm{M}=$ machos; ${ }^{*}=$ valor correspondente ao total de cada grupo; $\mathrm{FT}=$ filhotes; $\mathrm{AD}=$ adultos; $\mathrm{ID}=$ idosos; $\mathrm{NI}=$ não informado; $\mathrm{d}=$ dias; $\mathrm{m}$ = meses; $\mathrm{a}=$ anos; $\mathrm{HIC}=$ hepatite infecciosa canina; $\mathrm{CRD}=$ com raça definida; $\mathrm{SRD}=$ sem raça definida. 
ticas epidemiológicas (sexo, raça e idade) e seu significado clínico na rotina de diagnóstico na área de abrangência do Laboratório de Patologia Veterinária (LPV) da Universidade Federal de Santa Maria (UFSM).

\section{MATERIAL E MÉTODOS}

Os protocolos de necropsias de cães realizadas de janeiro de 1999 a dezembro de 2010 no LPV-UFSM foram revisados. Foram selecionados todos os casos em que havia uma ou mais lesões renais e/ou do trato urinário inferior (TUI). Dos protocolos de necropsia revisados foram anotados os dados relevantes referentes ao histórico clínico, epidemiologia (sexo, raça e idade), tipo de lesão do trato urinário, importância clínica das lesões (achado incidental, causa de morte espontânea [ME] ou razão para eutanásia [EUT]) e ocorrência de uremia. Em relação à faixa etária, os cães foram classificados como filhotes (menos de um ano de idade), adultos (1-9 anos de idade) ou idosos (10 anos de idade ou mais), conforme previamente realizado por Fighera et al. (2008). Quanto à raça, os cães foram divididos em com raça definida (CRD) ou sem raça definida (SRD).

As lesões foram pesquisadas e agrupadas conforme a sua distribuição no sistema urinário (lesões renais e do TUI) e classificadas de acordo com a literatura veterinária (Newman et al. 2007, Maxie \& Newman 2007). No rim, as lesões foram agrupadas e classificadas conforme apresentado no Quadro 1. No TUI, a classificação das lesões foi conforme apresentado no Quadro 2. Para as lesões mais prevalentes, tanto no rim quanto no TUI, foram pesquisadas nos protocolos de necropsia as principais doenças ou etiologias associadas.

\section{RESULTADOS}

De um total de 3.189 cães necropsiados num período de 12 anos (1999-2010) no LPV-UFSM, 1.063 apresentaram lesões no sistema urinário, correspondendo a uma prevalência de 33,3\%.

Dos 1.063 cães, $841(79,1 \%)$ apresentaram lesões únicas e $222(20,9 \%)$ tiveram lesões múltiplas no sistema urinário, totalizando 1.373 lesões. Deste total, 1.014 (73,8\%) lesões ocorreram no rim e $359(26,2 \%)$ no TUI. Quanto à importância clínica, 941 (68,5\%) lesões foram consideradas como achados incidentais de necropsia e $432(31,5 \%)$ foram causas de ME/EUT.

No Quadro 1, as 1.014 lesões renais estão classificadas conforme a sua distribuição e dispostas em ordem decrescente de prevalência. As características epidemiológicas (sexo, raça e idade) dos cães afetados também estão tabuladas.

As lesões túbulo-intersticiais predominaram, totalizando 420 ocorrências $(41,4 \%)$ representadas, em ordem decrescente de prevalência, por: nefrite túbulo-intersticial (236) (Fig.1), nefrite granulomatosa (112) (Fig.2), necrose tubular aguda (64) e presença de pigmento biliar no epitélio tubular (8).

Quadro 2. Prevalência e epidemiologia das lesões do trato urinário inferior (TUI) em 1.063 cães necropsiados no Laboratório de Patologia Veterinária da Universidade Federal de Santa Maria (LPV-UFSM) de janeiro de 1999 a dezembro de 2010 (12 anos)

\begin{tabular}{|c|c|c|c|c|}
\hline Lesões do TUI & №/\% & Sexo & Raça & Idade (mínima-máxima) \\
\hline Lesões inflamatórias & $122 * / 34$ & & & \\
\hline Cistite aguda & $69 / 56,6$ & $27 \mathrm{~F} ; 42 \mathrm{M}$ & 46 CRD; 23 SRD & 6 FT; 38 AD; 22 ID; 3 NI (2 m - 18 a) \\
\hline Cistite crônica & $43 / 35,2$ & $29 \mathrm{~F} ; 14 \mathrm{M}$ & 21 CRD; 22 SRD & 1 FT; 25 AD; 16 ID; 1 NI (4 m - 17 a) \\
\hline Ureterite (pioureter) & $4 / 3,3$ & $2 \mathrm{~F} ; 2 \mathrm{M}$ & 4 SRD & $3 \mathrm{AD} ; 1 \mathrm{ID}(4 \mathrm{a}-14 \mathrm{a})$ \\
\hline Lesões obstrutivas & $\mathbf{8 1} * / 22,6$ & & & \\
\hline Urolitíase & $51 / 63$ & $20 \mathrm{~F} ; 31 \mathrm{M}$ & 28 CRD; 23 SRD & 4 FT; 27 AD; 19 ID; 1 NI (45d-16a) \\
\hline Morbilivírus (cinomose) - bexiga & $59 / 100$ & $35 \mathrm{~F} ; 24 \mathrm{M}$ & 37 CRD; 22 SRD & 44 FT; 15 AD (22d-9a) \\
\hline Variações anatômicas adquiridas & $\mathbf{5 2 *} / 14,5$ & & & \\
\hline Dilatação da bexiga & $22 / 42,3$ & $5 \mathrm{~F} ; 17 \mathrm{M}$ & 13 CRD; 9 SRD & 3 FT; 10 AD; 8 ID; 1 NI (7 m - 18 a) \\
\hline Ruptura de bexiga & $19 / 36,5$ & $9 \mathrm{~F} ; 10 \mathrm{M}$ & $8 \mathrm{CRD} ; 11 \mathrm{SRD}$ & 2 FT; 12 AD; 4 ID; 1 NI (5 m-16 a) \\
\hline Retroflexão de bexiga & $7 / 13,5$ & $7 \mathrm{M}$ & 3 CRD; 4 SRD & $3 \mathrm{AD} ; 4$ ID $(4 a-12 a)$ \\
\hline Ruptura uretral & $2 / 3,9$ & $2 \mathrm{M}$ & 2 CRD & $1 \mathrm{AD} ; 1 \mathrm{ID}(5 \mathrm{a}-10 \mathrm{a})$ \\
\hline Estenose uretral & $1 / 1,9$ & $1 \mathrm{M}$ & $1 \mathrm{CRD}$ & $1 \mathrm{AD}(1 \mathrm{a})$ \\
\hline Primário epitelial (bexiga) & $7 / 20,6$ & $4 \mathrm{~F} ; 3 \mathrm{M}$ & 3 CRD; 4 SRD & $2 \mathrm{AD} ; 4 \mathrm{ID} ; 1 \mathrm{NI}(6 \mathrm{a}-15 \mathrm{a})$ \\
\hline Primário mesenquimal (bexiga) & $4 / 11,9$ & $1 \mathrm{~F} ; 3 \mathrm{M}$ & 3 CRD; 1 SRD & $1 \mathrm{AD} ; 2$ ID; 1 NI (AD - 12 a) \\
\hline Primário epitelial (uretra) & $1 / 2,9$ & $1 \mathrm{~F}$ & 1 CRD & 1 ID (12 a) \\
\hline Metastáticos/multicêntricos (uretra) & $1 / 2,9$ & $1 \mathrm{~F}$ & 1SRD & 1 ID (14 a) \\
\hline Primário mesenquimal (uretra) & $1 / 2,9$ & $1 \mathrm{~F}$ & $1 \mathrm{SRD}$ & $1 \mathrm{FT}(6 \mathrm{~m})$ \\
\hline Primário mesenquimal (ureter) & $1 / 2,9$ & $1 \mathrm{~F}$ & 1CRD & $1 \mathrm{AD}(8 \mathrm{a})$ \\
\hline Distúrbios circulatórios & $\mathbf{8}^{*} / 2,2$ & & & \\
\hline Hemorragia (bexiga) & $7 / 87,5$ & $5 \mathrm{~F} ; 2 \mathrm{M}$ & 5 CRD; 2 SRD & 2 FT; 3 AD; 2 ID (2 m - 13 a) \\
\hline Trombose (bexiga) & $1 / 12,5$ & $1 \mathrm{~F}$ & 1SRD & 1 ID $(10 a)$ \\
\hline Anomalias do desenvolvimento & $3 * / 0,8$ & & & \\
\hline Divertículo vesical & $2 / 66,7$ & $1 \mathrm{~F} ; 1 \mathrm{M}$ & $2 \mathrm{CRD}$ & $2 \mathrm{AD}(6 \mathrm{a}-8 \mathrm{a})$ \\
\hline Ureter ectópico & $1 / 33,3$ & $1 \mathrm{~F}$ & $1 \mathrm{SRD}$ & $1 \mathrm{AD}(4 \mathrm{a})$ \\
\hline Total & 359 & & & \\
\hline
\end{tabular}

F = fêmeas; $\mathrm{M}=$ machos; ${ }^{*}=$ valor correspondente ao total de cada grupo; $\mathrm{CRD}=$ com raça definida; $\mathrm{SRD}=$ sem raça definida; $\mathrm{FT}=$ filhotes; $\mathrm{AD}=$ adultos; $\mathrm{ID}=$ idosos; $\mathrm{NI}=$ não informado; $\mathrm{d}=$ dias; $\mathrm{m}$ = meses; $\mathrm{a}=$ anos. 


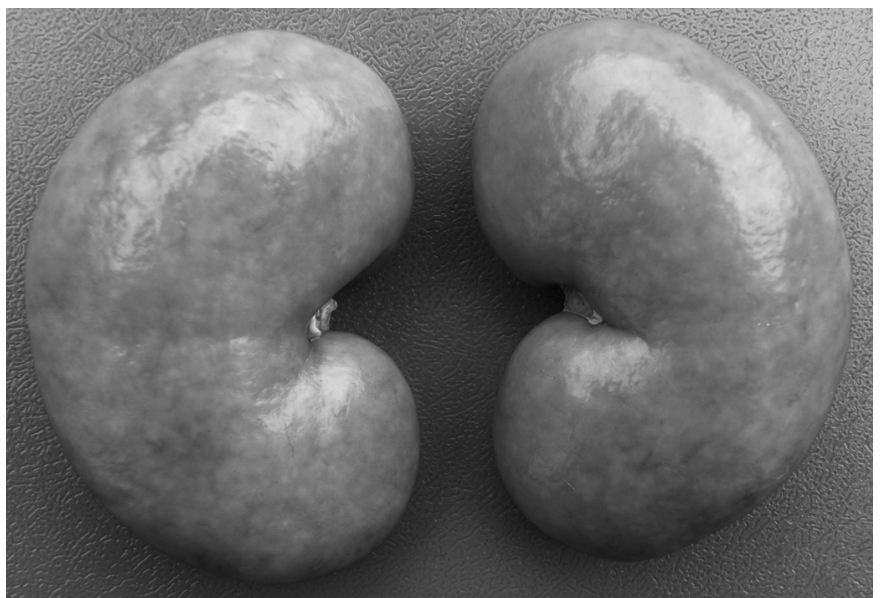

Fig.1. Nefrite túbulo-intersticial crônica. Ambos os rins estão difusamente pálidos. A superfície capsular está levemente irregular, com pequenas áreas irregulares brancacentas (fibrose).

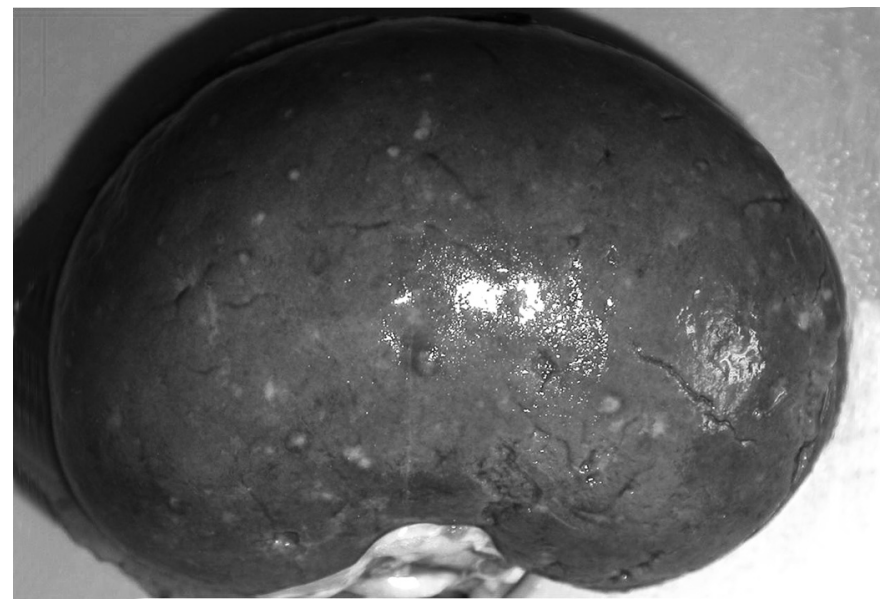

Fig.2. Nefrite granulomatosa (secundária à migração de larvas de Toxocara canis). Na superfície capsular há múltiplos pequenos nódulos brancacentos. Alguns deles são salientes na superfície.

Dos 236 casos de nefrite túbulo-intersticial, 155 (65,7\%) foram achados incidentais de necropsia, 81 (34,3\%) foram casos de ME/EUT (com 30 casos de uremia). Na grande maioria dos casos a causa específica da nefrite intersticial não foi determinada. Nefrite túbulo-intersticial atribuída à leptospirose foi diagnosticada em 29 casos (com seis casos de uremia); em alguns desses casos havia também áreas multifocais de necrose tubular. Em nove casos a nefrite túbulo-intersticial estava associada à rangeliose. Nove fêmeas com nefrite túbulo-intersticial haviam desenvolvido piometra recentemente. Destes nove casos, quatro apresentavam glomerulonefrite concomitantemente.

Dos 112 casos de nefrite granulomatosa, somente um caso de lesão acentuada foi associado à criptococose. Os demais foram lesões multifocais leves atribuídas à migração de larvas de Toxocara canis. Dos 112 casos, apenas o de criptococose sistêmica foi razão para eutanásia, os demais foram considerados achados incidentais.

Necrose tubular aguda (nefrose; NTA) foi diagnosticada em 64 cães. Destes, 14 casos eram de origem isquêmica e quatro de origem tóxica; 46 não foram classificados quan- to à origem. Dos 64 casos de NTA, 30 foram considerados como achado incidental e 34 (53,1\%) foram causa de ME/ EUT. Dezessete casos de NTA estavam associados à leptospirose, sete casos eram de nefrose hemoglobinúrica e sete casos eram de nefrose colêmica.

O grupo dos distúrbios circulatórios representou 22,4\% (227 casos) das lesões renais. Estas lesões, em ordem decrescente de prevalência, foram: infarto (158) (Fig.3), congestão/hiperemia (36), hemorragia (23), necrose da crista medular (9) (Fig.4) e trombose (1). Dos 158 casos de infarto renal, $29(18,3 \%)$ apresentaram endocardite valvar concomitante. Em 144 casos, os infartos renais foram considerados achados incidentais de necropsia e em 14 casos foram causa de ME/EUT (com quatro casos de uremia). Nos casos de hiperemia e congestão, as principais causas relacionadas foram choque neurogênico ou casos sugestivos de envenenamento. Os casos de hemorragia tiveram como principais causas o trauma (atropelamento) e também os casos sugestivos de envenenamento. Um caso de coagulação intravascular disseminada (CID) e um caso sugestivo

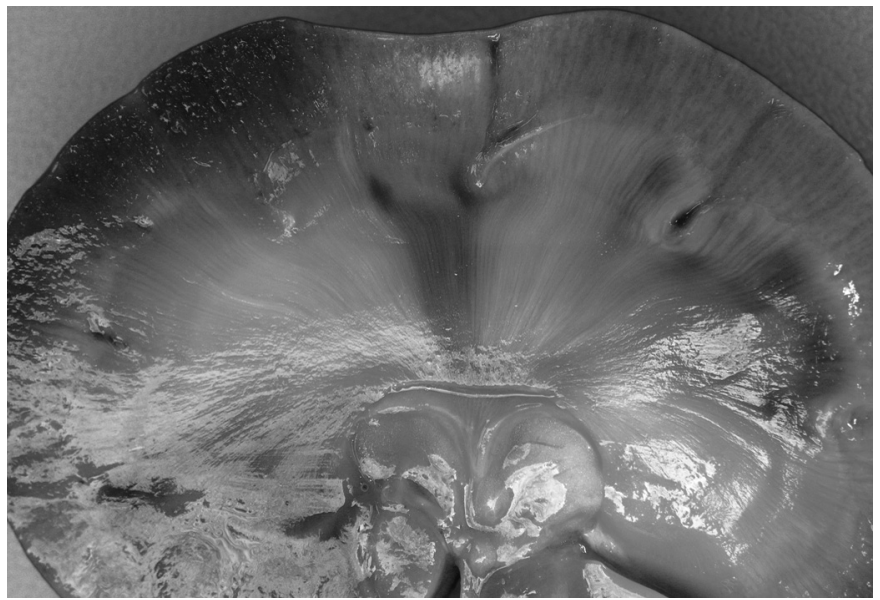

Fig.3. Infarto renal. Na superfície de corte observa-se área deprimida na camada cortical renal. Esta área é vermelho-clara, bem delimitada e em formato de cunha e se estende desde a cortical até a medular interna.

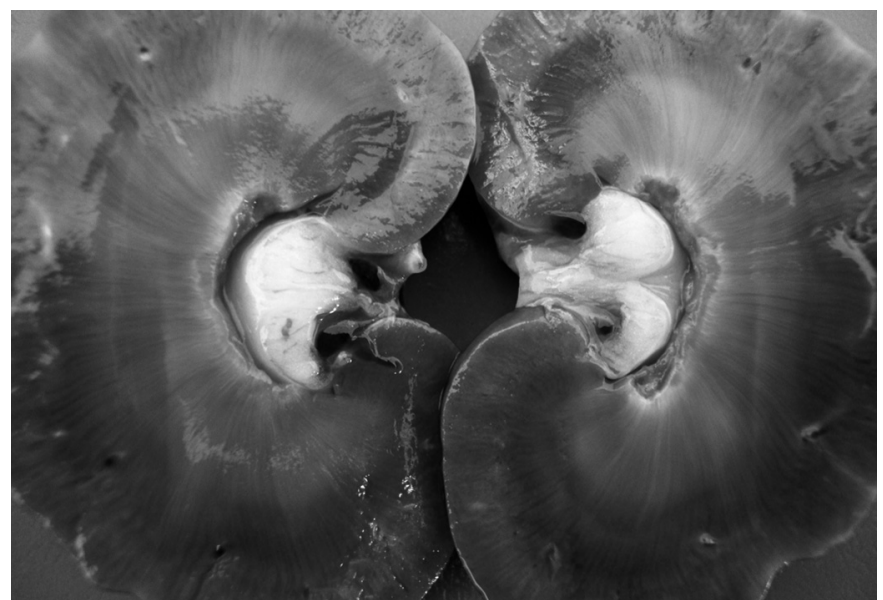

Fig.4. Necrose da crista medular renal. Em ambos os rins a crista medular apresenta áreas de erosão e perda tecidual acentuada (necrose). Observam-se ainda múltiplos pequenos infartos cicatrizados na camada cortical renal. 
de infecção por herpesvírus canino foram considerados também como causas de hemorragia. Três dos casos de necrose da crista medular foram associados ao tratamento com anti-inflamatórios não esteroidais (AINEs); nos demais casos a causa específica não foi determinada.

0 grupo das lesões glomerulares representou $11,1 \%$ (113 casos) das lesões renais e a glomerulonefrite (Fig.56), com 98 casos, foi a lesão mais frequente. Destes, 55 casos foram de glomerulonefrite membranoproliferativa, 26 de glomerulonefrite membranosa, três casos de glomerulonefrite proliferativa e os demais casos (14) não foram classificados quanto ao padrão histológico da lesão. Dos casos de glomerulonefrite, em 48 (49\%) as lesões foram consideradas achados incidentais e em 50 (51\%) casos houve ME/ EUT (com 31 casos de uremia). Dez cadelas com glomerulonefrite (sete do tipo membranoproliferativa e três do tipo membranosa) haviam desenvolvido piometra recentemente. Dos casos de glomerulonefrite associados com piometra, quatro apresentavam também nefrite intersticial.

Glomeruloesclerose (9), glomerulite supurativa (nefrite embólica aguda) (4), amiloidose glomerular (1) e glome- rulite fibrino-exsudativa (idiopática) (1) foram as demais alterações glomerulares observadas.

De um total de 98 lesões da pelve renal, pielite/pielonefrite (47 casos) (Fig.7) e hidronefrose (41 casos) (Fig.8) predominaram seguidas por pionefrose/abscesso perinéfrico ( 9 casos) e parasitas renais ( 2 casos). Trinta e três casos de pielonefrite foram considerados achados incidentais de necropsia e três foram de ME/EUT (com um caso de uremia). Os três casos de causa de ME/EUT estavam associados à cistite acentuada. Muitos casos de pielonefrite que foram considerados como achado incidental também eram lesões extensas, moderadas a acentuadas. Onze casos de pielite foram considerados como achado incidental de necropsia. Quase todos os cães com pielonefrite ou pielite apresentavam outras lesões do trato urinário simultaneamente, como por exemplo, urolitíase e/ou cistite.

Dezoito casos de hidronefrose foram considerados como achado incidental de necropsia e 23 foram de ME/EUT (com seis casos de uremia). As principais causas de obstrução do fluxo urinário com consequente hidronefrose foram, em ordem decrescente de prevalência, neoplasmas primários ou
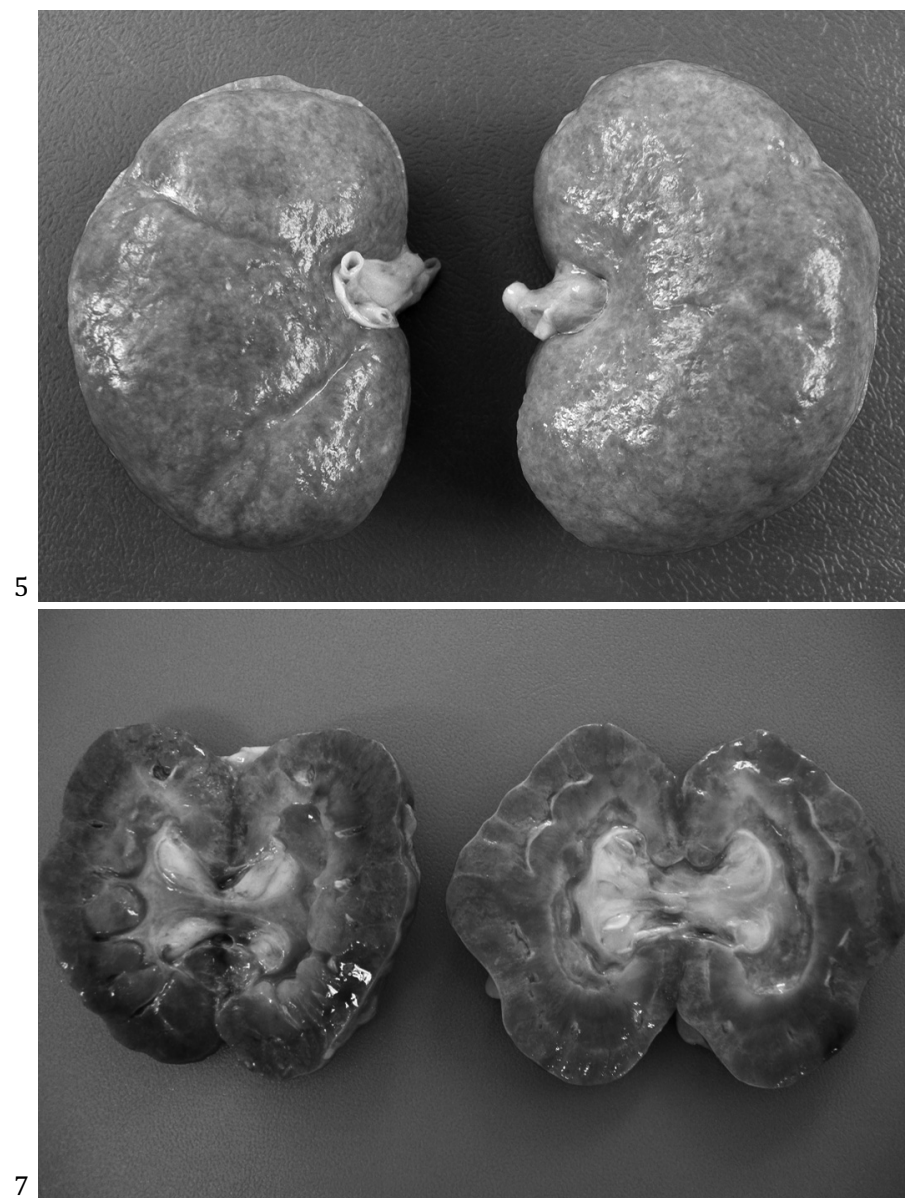

Fig.5. Glomerulonefrite crônica (superfície capsular). Ambos os rins estão difusamente pálidos e a superfície capsular apresenta aspecto irregular (finamente granular).

Fig.7. Pielonefrite difusa acentuada bilateral. Em ambos os rins a pelve renal está dilatada e apresenta exsudato purulento. Há áreas de necrose com perda de parênquima na camada medular. 0 contorno cortical está acentuadamente irregular.
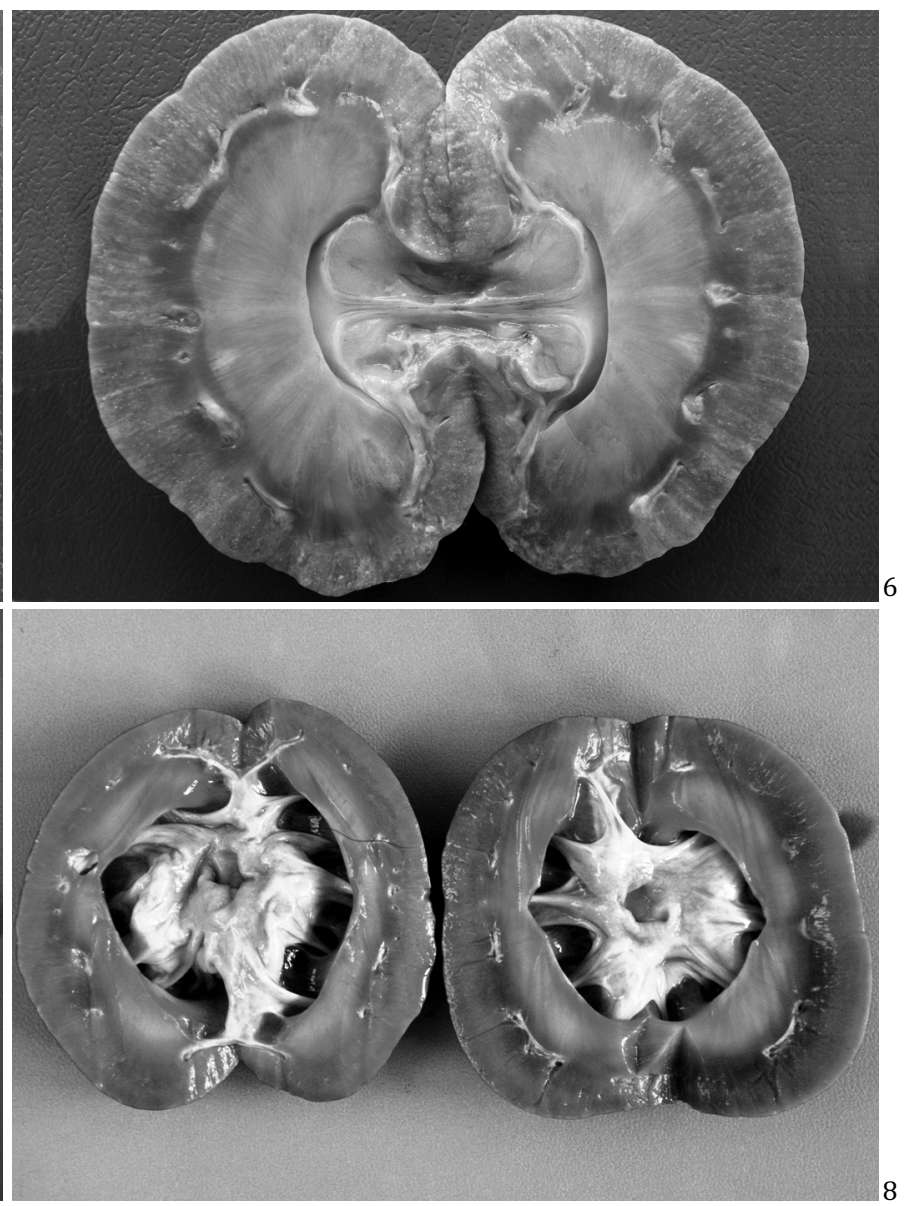

Fig.6. Glomerulonefrite crônica (superfície de corte). 0 rim está difusamente pálido. 0 contorno cortical está levemente irregular. As camadas, medular externa e interna, estão difusamente brancacentas devido à fibrose intersticial.

Fig.8. Hidronefrose difusa acentuada bilateral. Em ambos os rins a pelve está acentuadamente dilatada. Há atrofia bilateral difusa da camada medular com exposição dos septos conjuntivos. 

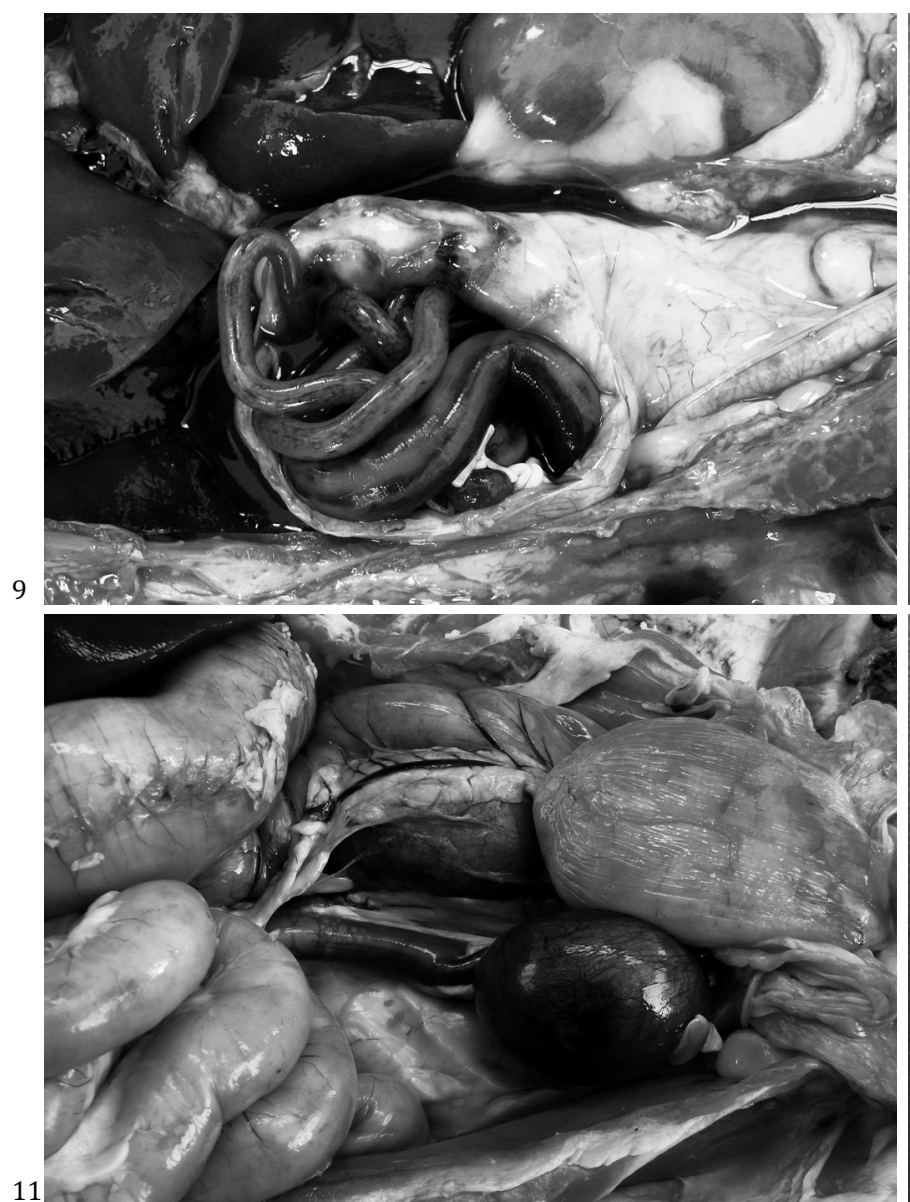

Fig.9. Parasitismo renal por Dioctophyma renale. Rim direito (aberto) com atrofia difusa acentuada do parênquima (reduzido à uma capsula fibrosa) e presença de nematódeos com morfologia compatível com D. renale.

Fig.11. Ectopia renal. 0 rim direito está localizado próximo à bexiga e o pólo caudal deste está recoberto por ela. 0 rim esquerdo também está deslocado caudalmente, embora em menor intensidade.

metastáticos localizados na bexiga e ureter, urolitíase uretral, prostatite, retroflexão dorsal da bexiga e atonia vesical secundária à degeneração da medula espinhal. 0 parasitismo renal foi por Dioctophyma renale (Fig.9-10).

Quanto aos neoplasmas renais, os metastáticos/multicêntricos (69 casos) predominaram. Metástases de neoplasmas mamários predominaram com 22 casos (32\%); a seguir vieram hemangiossarcoma (10; 14,5\%), linfoma (8; $11,6 \%)$, osteossarcoma $(4 ; 5,8 \%)$ e, com três $(4,3 \%)$ casos cada, sarcoma histiocítico, sarcoma indiferenciado e mastocitoma. Os demais $(16 ; 23,2 \%)$ neoplasmas metastáticos/multicêntricos foram de histogênese variada e representados por um ou dois casos cada. Os neoplasmas primários renais de origem epitelial ocorreram em somente cinco casos representados por: carcinoma renal (3 casos), cistadenoma (1) e cistadenocarcinoma (1). Os dois últimos como parte da síndrome hereditária da raça Pastor Alemão, associada à dermatofibrose nodular.

Das anomalias do desenvolvimento renal, 32 casos foram de cistos renais, três casos de rins ectópicos (Fig.11),
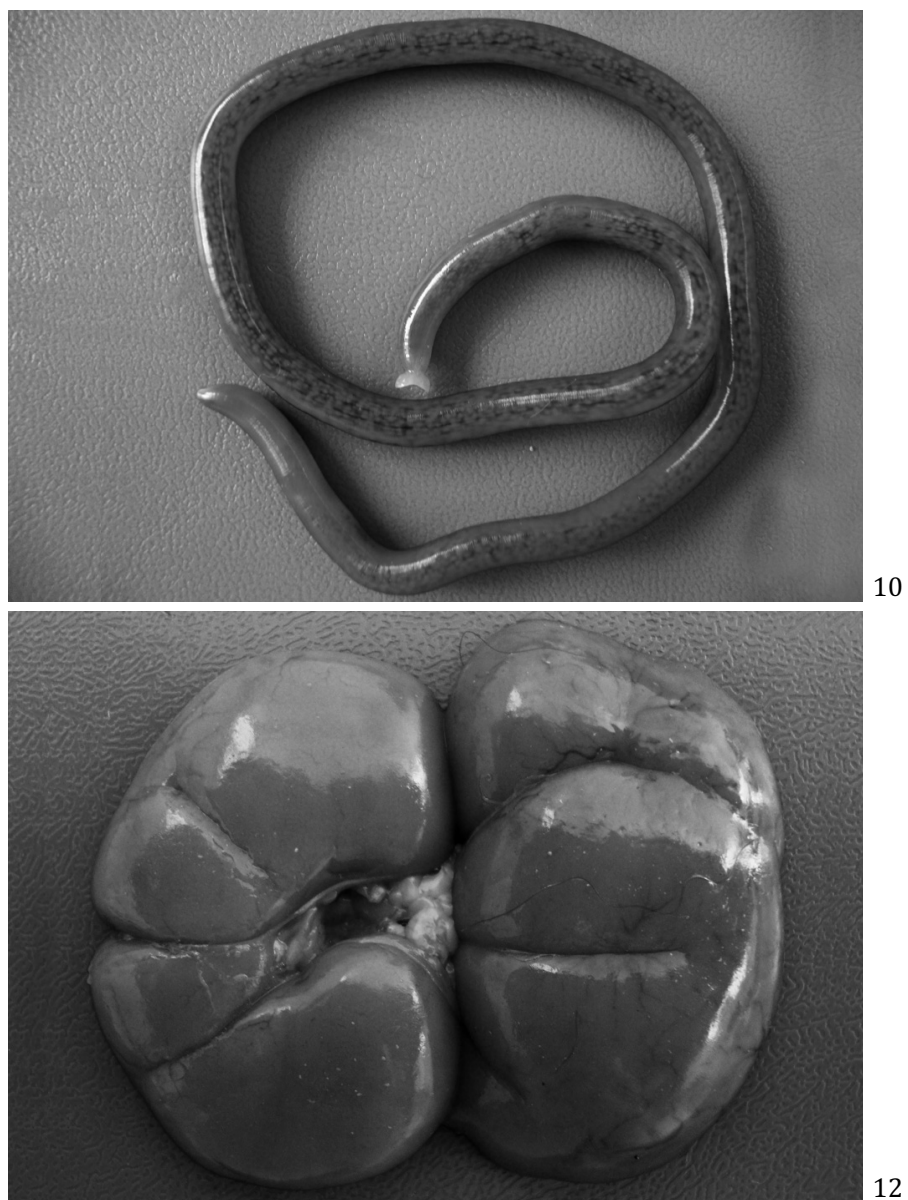

Fig.10. Exemplar de Dioctophyma renale. Recuperado do cão da Figura 9. Nematódeo com morfologia consistente com $D$. renale. Trata-se de um exemplar macho, pois apresenta a bolsa copuladora característica em uma das extremidades (centro da foto).

Fig.12. Rim, persistência da lobulação fetal. Na superfície capsular observam-se sulcos profundos que dividem o parênquima renal.

dois de agenesia renal, dois de persistência da lobulação fetal (Fig.12) e um caso de displasia renal. Não foi possível determinar quantos casos foram de cistos renais congênitos e quantos foram de cistos adquiridos.

No grupo presença de inclusões virais, 15 casos foram de inclusões de morbilivírus (cinomose) no urotélio da pelve renal e 10 foram de adenovírus canino tipo 1 (hepatite infecciosa canina) no núcleo das células dos capilares dos tufos glomerulares.

Fibrose renal difusa (Fig.13-14) ocorreu em 13 casos, sendo que em três deles a lesão foi atribuída à condição denominada nefropatia juvenil progressiva, acometendo três filhotes (um Lhasa Apso de 40 dias, um Cocker Spaniel de quatro meses e um Australian Cattle Dog de 11 meses). Em 11 desses casos $(84,6 \%)$ a fibrose renal estava relacionada com a ME/EUT (com oito casos de uremia). Em cinco casos as lesões foram caracterizadas como "rim em estágio terminal". No grupo "presença de protozoários" houve três casos de presença de Rangelia vitalli, sem reação inflamatória associada no rim. 


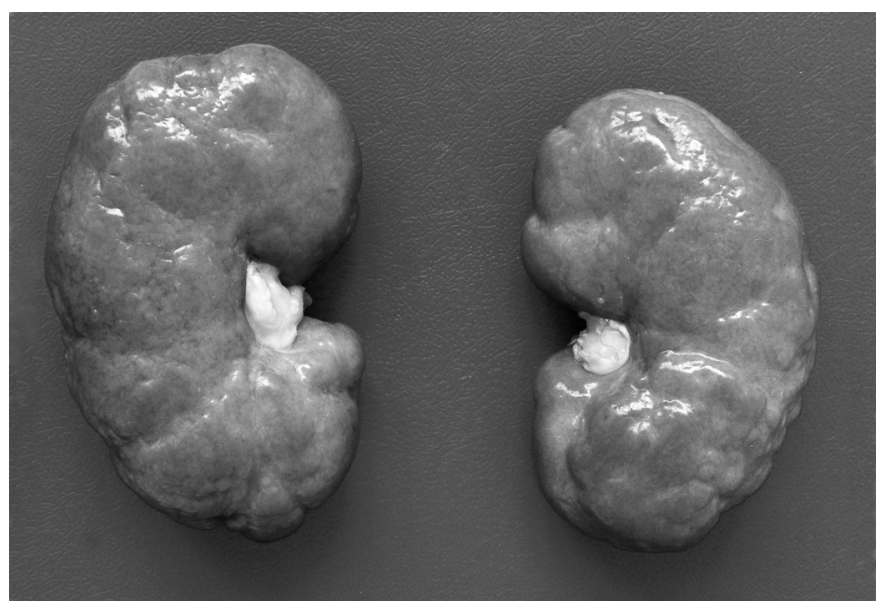

Fig.13. Fibrose renal difusa (superfície capsular). A superfície capsular está marcadamente irregular, apresentando áreas multifocais a coalescentes brancacentas e deprimidas.

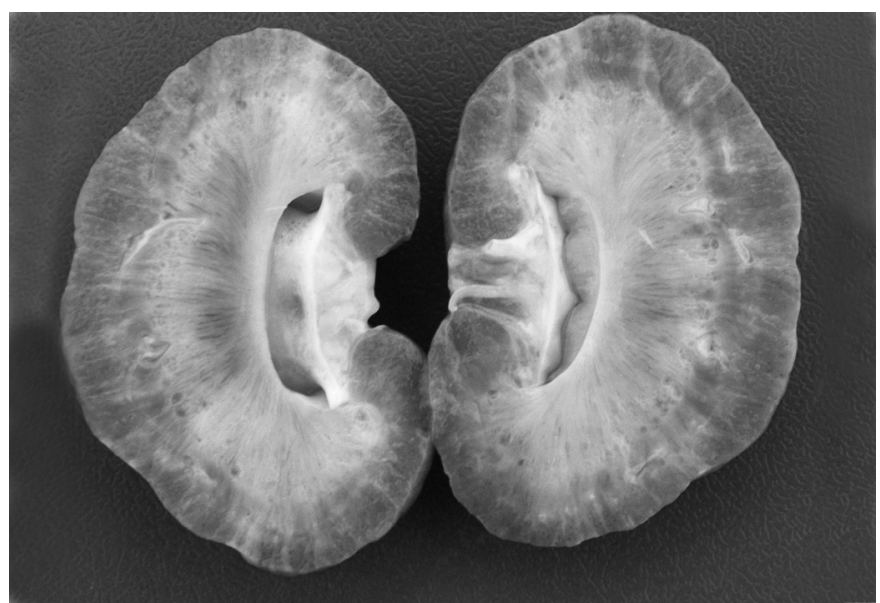

Fig.14. Fibrose renal difusa (superfície de corte). O contorno da camada cortical está irregular, com áreas deprimidas (atrofia cortical). Há múltiplos e pequenos cistos (de retenção) na junção córtico-medular. A medular está brancacenta com áreas lineares vermelhas. A pelve está levemente dilatada.

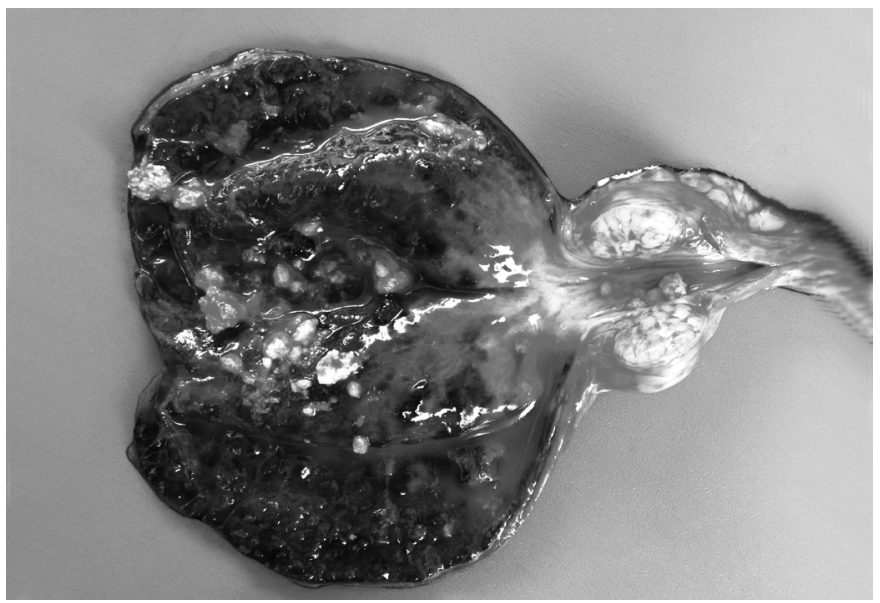

Fig.15. Cistite fibrinonecro-hemorrágica associada à urolitíase. A parede vesical está espessada. Na mucosa há hemorragia difusa acentuada com coágulos sanguíneos aderidos à superfície. Há conteúdo sanguinolento e vários cálculos branco-amarelados com superfície irregular. Na uretra prostática há cálculos semelhantes de tamanhos variados.
As 359 lesões do TUI estão listadas no Quadro 2, em ordem decrescente de prevalência. As características epidemiológicas dos cães afetados também estão tabuladas.

Das 122 (34\%) lesões inflamatórias do TUI, 112 foram casos de cistite. Sessenta e nove foram casos de cistite aguda (Fig.15) e 43 de cistite crônica. Na maioria dos casos a cistite aguda não estava relacionada com lesões graves do TUI, entretanto em $18(16,1 \%)$ casos ela foi secundária à obstrução do fluxo urinário. Consequências como ruptura de bexiga com uroperitônio foram observadas em alguns casos. Em quatro casos houve uremia. Todos os 43 casos de cistite crônica foram considerados como achado incidental de necropsia. As principais causas de cistite incluíram: urolitíase (vesical e uretral) (Fig.15), prostatite, hérnia perineal com retroflexão dorsal da bexiga e estase urinária devido à compressão medular secundária à protrusão de disco intervertebral. Uretrite e ureterite representaram 10 casos.

Das lesões obstrutivas (81 casos; 22,6\%), havia 51 casos de urolitíase (Fig.15) e 30 de hidroureter (Fig.16). Quarenta e um casos $(80,4 \%)$ de urolitíase foram considerados como achado incidental de necropsia e $10(19,6 \%)$ foram causa de ME/EUT (com seis casos de uremia).

A presença de inclusões virais foi observada no urotélio vesical e constituída de $59(16,4 \%)$ casos de inclusões eosinofílicas intracitoplasmáticas características de infecção por morbilivírus (cinomose).

No grupo das variações anatômicas adquiridas (52 casos; 14,5\%), 22 casos foram de dilatação vesical (Fig.17), 19 casos de ruptura de bexiga (com uroperitônio) (Fig.18), sete casos de retroflexão de bexiga, um caso de ruptura uretral, um caso de estenose uretral e um de estenose ureteral.

Em 34 (9,5\%) casos de neoplasmas do TUI, predominaram os metastáticos/multicêntricos (20 casos). Oito casos foram neoplasmas primários epiteliais e seis foram primários mesenquimais. Na bexiga o carcinoma mamário $(5$ casos) foi o neoplasma metastático mais prevalente e o carci-

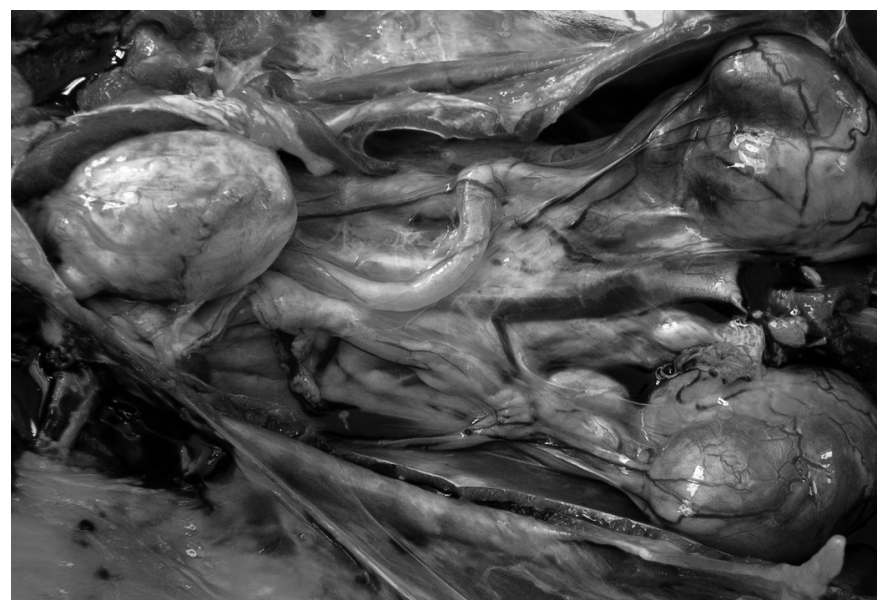

Fig.16. Hidroureter bilateral. Ambos os ureteres estão marcadamente aumentados de volume. A obstrução do fluxo urinário neste caso ocorreu pela presença de um carcinoma de células de transição na região do trígono vesical, o qual obstruía os óstios ureterais. Nota-se que os rins também estão aumentados de volume (área da pelve) devido à hidronefrose bilateral (cão da Figura 8). 


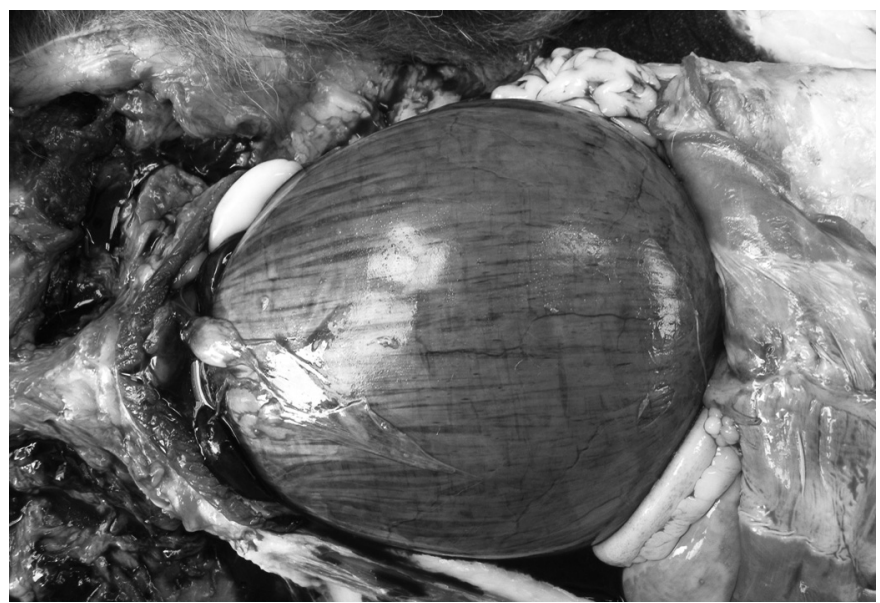

Fig.17. Dilatação vesical acentuada. Havia uma massa preenchendo a cavidade pélvica que correspondia a uma metástase de hemangiossarcoma. A massa metastática comprimiu externamente a uretra pélvica, causando obstrução do fluxo urinário.

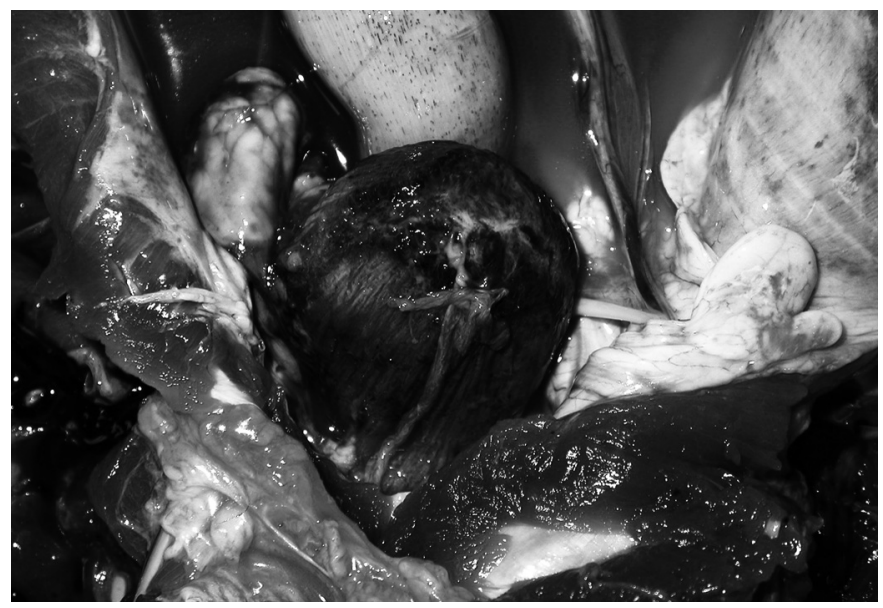

Fig.18. Ruptura de bexiga com uroperitônio. Na superfície serosa da região do fundo vesical há área focalmente extensa vermelho-escura e recoberta por filamentos de fibrina (área de ruptura vesical). Observa-se líquido serosanguinolento livre na cavidade abdominal (uroperitônio) e hemorragias multifocais na serosa do intestino grosso e no peritônio e tecido adiposo do lado direito (peritonite química).

noma de células de transição (CCT) foi o primário epitelial que predominou ( 7 casos). Entre os neoplasmas primários de origem mesenquimal, predominou o leiomioma vesical.

No grupo dos distúrbios circulatórios $(8 ; 2,2 \%)$ ocorreram sete casos de hemorragia e um de trombose, todos localizados na bexiga. Os casos de hemorragia foram secundários principalmente a trauma causado por atropelamento. 0 caso de trombose foi observado em uma fêmea com coagulação intravascular disseminada. Dos casos de anomalias do desenvolvimento $(3 ; 0,8 \%)$ no TUI, havia dois casos de divertículo vesical e um caso de ureter ectópico.

\section{DISCUSSÃO}

Através deste estudo constatou-se que um terço, de um total de 3.189 cães necropsiados em um período de 12 anos no LPV-UFSM, apresentou algum tipo de lesão no sistema urinário, demonstrando a importância da avaliação criteriosa dos órgãos e tecidos que constituem esse sistema na rotina de necropsia de cães. 0 estudo permitiu também o estabelecimento da prevalência e do significado clínico da maioria das lesões diagnosticadas nos rins e no TUI. Foi possível constatar que $31 \%$ das lesões encontradas no sistema urinário foram causa de ME/EUT. Muitas vezes a etiologia específica também pode ser estabelecida.

Os rins foram 2,8 vezes mais afetados que o TUI. Nefrite túbulo-intersticial é observada, na maioria das vezes, como um achado incidental e não associada com insuficiência renal (Newman et al. 2007). Neste estudo, apesar da maioria dos casos de nefrite túbulo-intersticial ser considerada um achado incidental de necropsia e não ter a etiologia específica determinada, houve um número expressivo de casos de ME/EUT (34,3\%) associados a essa lesão e destes, 37\% resultaram em uremia. Nefrite túbulo-intersticial, atribuída à leptospirose pelas características morfológicas, foi observada em 35,8\% dos casos de ME/EUT anteriormente mencionados. Esta lesão é descrita em cães com sorologia positiva para Leptospira spp., e os sorovares mais frequentes em diferentes populações caninas são icterohaemorrhagiae (Bueno de Camargo et al. 2006) e canicola (Ortega-Pacheco et al. 2008). Outros sorovares também descritos em cães incluem pommona (Birnbaum et al. 1998, Cowgill \& Elliott 2008), bratislava (Cowgill \& Elliott 2008) e grippotyphosa (Birnbaum et al. 1998; Wild et al. 2002, Cowgill \& Elliott 2008). Inicialmente a lesão renal é de necrose tubular aguda e a nefrite túbulo-intersticial surge quando o curso da doença é mais avançado (Newman et al. 2007).

Neste estudo, nove fêmeas com nefrite túbulo-intersticial haviam desenvolvido piometra recentemente. É descrito que cadelas com piometra podem apresentar lesões túbulo-intersticiais com maior frequência do que glomerulonefrite (Heiene et al. 2007, Maxie; Newman 2007). Entretanto, o mecanismo da lesão túbulo-intersticial relacionada com piometra não está esclarecido.

Nefrite granulomatosa em cães é geralmente secundária à migração de larvas de Toxocara canis e é considerada a lesão parasitária renal mais comum (Maxie \& Newman 2007). A maioria dos casos deste estudo ocorreu em cães adultos (64,2\% dos afetados).

Neste estudo, vários casos de necrose tubular aguda (NTA) foram atribuídos à leptospirose $(26,6 \%)$. A NTA é uma importante causa de insuficiência renal aguda (Newman et al. 2007, Cowgill \& Elliott 2008). Entretanto, em muitos casos não é possível determinar a causa da NTA através dos achados microscópicos, fato este constatado neste estudo, já que 51,6 \% dos casos não tiveram a causa específica determinada. Causas de lesões túbulo-intersticiais em cães raramente são estabelecidas. Este fato está relacionado com a relação funcional interdependente entre os componentes do néfron. Assim, há o desenvolvimento de lesões em porções inicialmente não afetadas pela injúria (Polzin et al. 2008).

Nos distúrbios circulatórios, o infarto renal foi a lesão mais representada. A grande maioria dos infartos $(91,1 \%)$ foi considerada como achado incidental de necropsia. Nestes casos não havia comprometimento de grandes áreas de 
parênquima renal. Infartos renais ocorrem mais frequentemente devido à obstrução de pequenos vasos (como as artérias inter-lobulares) levando a múltiplos e pequenos infartos que afetam somente o córtex renal e não causam lesões muito extensas (Newman et al. 2007). Os cinco casos com infarto renal acentuado, observados neste estudo foram secundários à endocardite valvar vegetante e foram causa de ME. Nestes casos, uma maior extensão do parênquima renal foi afetada, contribuindo para a morte dos cães. Estudos que descreveram casos de endocardite valvar (bacteriana) em cães apontaram o rim como o principal órgão afetado por múltiplos e extensos infartos (Spagnol et al. 2006, Fighera et al. 2007).

Dentre as lesões glomerulares, a glomerulonefrite predominou. Como observado no Quadro 1, cães adultos e idosos apresentaram glomerulonefrite, enquanto nenhum filhote foi afetado. Glomerulonefrite imunomediada foi descrita em cães idosos (Rouse \& Lewis 1975, Lewis 1976, Schoning \& Cowan 1993), enquanto que um estudo em rim de filhotes não demonstrou deposição de imunocomplexos nos glomérulos. Uma hipótese para explicar este resultado seria a de que os cães mais velhos tiveram mais tempo de exposição aos antígenos desencadeadores do mecanismo imunológico da glomerulonefrite (Lewis 1976).

Glomerulonefrite é considerada uma lesão importante em cães que pode anteceder a falha renal (com uremia) e o rim em estágio terminal (Maxie \& Newman 2007). A deposição de imunocomplexos nos glomérulos é o principal mecanismo desencadeador, que pode ocorrer em cães com doenças auto-imunes (como lúpus eritematoso sistêmico), em infecções persistentes (como nos casos de piometra, leishmaniose e dirofilariose) ou em cães com neoplasmas (Costa et al. 2003, Maxie \& Newman 2007, Newman et al. 2007, Serakides 2010). Cães adultos e idosos podem apresentar deposição de imunocomplexos nos glomérulos, sem, no entanto apresentar sinais de doença renal (Rouse \& Lewis 1975). Possivelmente parte dos $49 \%$ dos casos de glomerulonefrite considerados como achado incidental vistos no presente estudo se enquadre nesta situação.

Em medicina veterinária, os tipos morfológicos das glomerulonefrites não são comumente associados com a apresentação clínica, curso clínico ou resolução, como observado em humanos. Sabe-se que o tipo mais frequente em cães é a glomerulonefrite membranoproliferativa (Maxie \& Newman 2007, Serakides 2010). No presente trabalho, $56 \%$ dos casos de glomerulonefrite foram do tipo membranoproliferativa.

Os neoplasmas constituíram o quinto grupo de lesões mais prevalentes no rim e também no TUI. Um estudo retrospectivo realizado por Inkelmann et al. (2011), incluindo os casos aqui descritos, permitiu detalhar os aspectos mais relevantes desta condição nos cães afetados.

Dentre as lesões da pelve renal, pielonefrite/pielite foi a mais frequentemente observada. Em muitos casos de pielonefrite e em alguns de pielite acentuada havia cistite e urolitíase concomitantemente. 0 mecanismo que envolve a ocorrência da pielonefrite nestes casos é o refluxo urinário vesicoureteral durante a micção, principalmente em casos de infecção do TUI (cistite) e obstrução urinária, o que leva a urina contaminada até a pelve renal (Maxie \& Newman 2007, Newman 2007, Serakides 2010).

Hidronefrose afetou aproximadamente $41 \%$ dos cães do grupo das lesões da pelve renal. A obstrução do fluxo urinário ocorreu principalmente por urolitíase e pela presença de neoplasmas (primários ou metastáticos/multicêntricos) no TUI. Machos e fêmeas foram afetados em igual número. Entretanto, as fêmeas apresentaram mais neoplasmas que impediram parcialmente o fluxo urinário, enquanto os machos tiveram a obstrução por urólitos como principal causa da hidronefrose. Obstrução do fluxo urinário por urólitos em cães machos é frequentemente descrita (Newman et al. 2007, Del Angel-Caraza et al. 2010). Entretanto, não há justificativa para uma maior prevalência de fêmeas com neoplasmas do trato urinário inferior. Segundo a literatura, em relação aos neoplasmas primários vesicais não há predileção por sexo (Meuten 2002, Sapierzynski et al. 2007). Hidronefrose acometeu principalmente cães adultos e idosos. Este resultado está ligado diretamente ao fato de que um maior número de adultos e idosos desenvolveu as duas principais causas de hidronefrose que são neoplasmas e urolitíase obstrutiva. Neste estudo, outras causas como prostatite (com hiperplasia prostática), retroflexão vesical e atonia vesical (por lesão da medula espinhal, com consequente estase urinária) levaram ao desenvolvimento de hidronefrose devido à obstrução do fluxo urinário.

As anomalias do desenvolvimento, tanto no rim como no TUI, foram pouco prevalentes. Este resultado era esperado, pois estas alterações em geral são infrequentes em todas as espécies domésticas incluindo os cães (Agut et al. 2002, Newman et al. 2007, Hünning et al. 2009, Serakides 2010).

Inclusões virais de morbilivírus (cinomose) no urotélio da pelve renal e de adenovírus canino tipo 1 (hepatite infecciosa canina = HIC) no tufo glomerular foram observadas em filhotes e em adultos. Estas doenças são pouco frequentes em cães idosos (Inkelmann et al. 2007, Silva et al. 2007) e no período estudado nenhum cão idoso apresentou inclusões de HIC ou de cinomose no rim.

Apesar de ser diagnosticada em apenas 1,3\% dos cães deste estudo, a fibrose renal difusa foi a lesão mais fatal $(84,6 \%)$ levando ao desenvolvimento de uremia em $72,7 \%$ desses casos. Esta lesão é associada comumente com falha renal crônica e rim em estágio terminal, mas sabe-se que raramente a causa primária pode ser determinada (Maxie \& Newman 2007, Polzin et al. 2008).

De todas as lesões do TUI, as inflamatórias predominaram (34\%). Cistite aguda foi a principal lesão desenvolvida com $56 \%$ das lesões deste grupo. Nos casos de cistite aguda deste estudo houve um maior número de machos (61\%) afetados do que de fêmeas (39\%). As causas que levaram a cistite nestes casos foram variadas e incluíram: urolitíase (vesical e uretral), prostatite, hérnia perineal com retroflexão dorsal da bexiga e estase urinária devido à compressão medular secundária a protrusão de disco intervertebral. Dos 27 casos de cistite aguda em fêmeas foram observados alguns casos de compressão medular secundária à lesão de disco intervertebral, que levaram à estase urinária, como visto em alguns machos. Nos casos de cistite crônica predominaram 
fêmeas adultas e a grande maioria dos casos não teve uma etiologia determinada. Em geral fêmeas têm maior incidência de casos de cistite devido à uretra curta em comparação com os machos que têm uretra mais longa e mais estreita, o que constitui maior barreira para as infecções ascendentes (Maxie \& Newman 2007, Newman et al. 2007). Entretanto, nos casos de cistite aguda deste estudo (com predomínio de machos), ocorreram outras lesões que favoreceram o desenvolvimento desta lesão vesical devido à obstrução do fluxo urinário, com consequente estase urinária.

Neste estudo, os casos de urolitíase (aqui incluindo a pelve renal) predominaram (63\%) no grupo das lesões obstrutivas. Informações mais abrangentes podem ser obtidas no estudo retrospectivo de Inkelmann et al. (2012), o qual inclui, dentre outros, os casos aqui revisados. Urolitíase pode ter consequências graves em casos de obstrução parcial ou total do fluxo urinário (Newman et al. 2007), podendo ser causa de ME/EUT (Fighera et al.2008), como observado em alguns casos deste estudo. Por outro lado a presença dos urólitos pode não ser percebida clinicamente nos casos não obstrutivos (Osborne et al. 1996), como observado também neste estudo.

No Quadro 2 pode-se observar a prevalência de inclusões intracitoplasmáticas de morbilivírus (cinomose) na bexiga, principalmente de filhotes na população estudada. Cinomose afeta predominantemente filhotes e a bexiga é um dos principais órgãos para o diagnóstico (Sonne et al. 2009).

Das variações anatômicas adquiridas, nota-se no Quadro 2, que os machos foram os mais afetados por: dilatação de bexiga, ruptura de bexiga e retroflexão dorsal da bexiga. Dilatação e ruptura estavam associadas com urolitíase. Casos de retroflexão de bexiga em machos estão associados geralmente com aumento de volume prostático e também em casos de hérnia perineal (Maxie \& Newman 2007), que também foram observados em alguns dos casos do presente estudo.

Os resultados demonstram que muitas vezes a uremia esteve associada com as lesões do sistema urinário que foram causa de ME/EUT. Lesões acentuadas do sistema urinário podem causar uremia devido à azotemia prolongada. Qualquer que seja a situação que leve à azotemia (pré-renal, renal ou pós-renal), a excreção de metabólitos fica comprometida e pode haver desenvolvimento de sinais clínicos e lesões extrarrenais de uremia (Polzin et al. 2008, Cowgill \& Elliott 2008). Neste estudo a grande maioria das lesões que culminaram em uremia foram lesões renais e, dentre elas, a fibrose difusa, a glomerulonefrite e a nefrite túbulo-intersticial foram as principais. As lesões do TUI também contribuíram com a ocorrência de uremia e as principais lesões associadas foram cistite e urolitíase. Obstrução no TUI pode levar a uremia principalmente em casos de urolitíase uretral obstrutiva (Newman et al., 2007).

Quando analisados conjuntamente os cães com lesões renais e/ou no TUI, foi observado que predominaram cães CRD (57\%) sobre os SRD (43\%). Entretanto, como não são conhecidas as raças predominantes na população de cães da área de abrangência do LPV-UFSM, não foi possível uma análise adequada deste parâmetro.

\section{CONCLUSÕES}

O estudo das lesões do sistema urinário de cães necropsiados no LPV-UFSM num período de 12 anos permitiu concluir que:

a) um terço dos cães necropsiados apresentou algum tipo de lesão no sistema urinário;

b) um terço das lesões no sistema urinário dos cães necropsiados foram causa de ME/EUT;

c) as principais lesões renais diagnosticadas, em ordem decrescente de prevalência, foram: nefrite túbulo-intersticial, infarto, nefrite granulomatosa (parasitária), glomerulonefrite, neoplasmas metastáticos/multicêntricos, pielonefrite/pielite e hidronefrose;

d) as principais lesões do TUI diagnosticadas, em ordem decrescente de prevalência, foram: cistite, presença de inclusões virais (morbilivírus), urolitíase, dilatação da bexiga, ruptura da bexiga (com uroperitônio) e neoplasmas metastáticos/multicêntricos;

e) características epidemiológicas como sexo, raça e idade tiveram grandes variações de acordo com o tipo de lesão apresentada; e

f) uremia foi observada em um número expressivo de casos de ME/EUT e foi principalmente secundária a lesões renais.

Agradecimentos.- M.A. Inkelmann e M.E. Trost são bolsistas da Coordenação de Aperfeiçoamento de Pessoal de Nível Superior (CAPES). G.D. Kommers é bolsista de produtividade em pesquisa (PQ-Nível 2) do CNPq.

\section{REFERÊNCIAS}

Agut A., Fernandez Del Palacio J., Laredo F.G., Murciano J., Bayon A. \& Soler M. 2002. Unilateral renal agenesis associated with additional congenital abnormalities of the urinary tract in a Pekingese bitch. J. Small Anim. Pract. 43:32-35.

Birnbaum N., Barr S.C., Center S.A., Schermerhorn T., Randolph J.F. \& Simpson K.W. 1998. Naturally acquired leptospirosis in 36 dogs: Serological and clinicopathological features. J. Small Anim. Pract. 39:231-236.

Bueno de Camargo M.H., Moraes J.R.E., Carvalho M.B., Ferraro G.C. \& Palmeira Borges V. 2006. Alterações morfológicas e funcionais dos rins de cães com insuficiência renal crônica. Arq. Bras. Med. Vet. Zootec. 58(5):781-787.

Costa F.A.L., Goto H., Saldanha L.C.B., Silva S.M.M.S., Sinhorini I.L., Silva T.C. \& Guerra J.L. 2003. Histopathologic patterns of nephropathy in naturally acquired canine visceral leishmaniasis. Vet Pathol. 40:677-684.

Cowgill L.D. \& Elliott D.A. 2008. Insuficiência renal aguda, p.1701-1721. In: Ettinger S.J. \& Feldman E.C. (Eds), Tratado de Medicina Interna Veterinária: doenças do cão e do gato. Vol.2. $5^{\text {a }}$ ed. Guanabara Koogan, Rio de Janeiro.

Del Angel-Caraza J., Diez-Prieto I., Pérez-García C.C. \& García-Rodríguez M.B. 2010. Composition of lower urinary tract stones in canines in Mexico City. Urol. Res. 38:201-204.

Fighera R.A., Souza T.M., Irigoyen L.F. \& Barros C.S.L. 2007. Aspectos epidemiológicos e clinicopatológicos de 72 casos de endocardite valvar em cães. Clínica Vet. 67:60-67.

Fighera R.A., Souza T.M., Silva M.C., Brum J.S., Graça D.L., Kommers G.D., Irigoyen L.F. \& Barros C.S.L. 2008. Causas de morte e razões para eutanásia de cães da Mesorregião do Centro Ocidental Rio-Grandense (19652004). Pesq. Vet. Bras. 28(4):223-230.

Fleming J.M., Creevy K.E. \& Promislow D.E.L. 2011. Mortality in North American Dogs from 1984 to 2004: An investigation into age, size and breed-related causes of death. J. Vet. Intern. Med. 25:187-198.

Heiene R., Kristiansen V., Teige J. \& Jansen J.H. 2007. Renal histomorpho- 
logy in dogs with piometra and control dogs, and long term clinical outcome with respect to signs of kidney disease. Acta Vet. Scandinavica (4) 49:13.

Hünning P.S., Aguiar J., Lacerda L.A., Sonne L., Oliveira E.C. \& Haas G.F. 2009. Displasia renal em um cão. Acta Scientiae Veterinariae 37(1):73-77.

Inkelmann M.A., Rozza D.B., Fighera R.A., Kommers G.D., Graça D.L., Irigoyen L.F. \& Barros C.S.L. 2007. Hepatite infecciosa canina: 62 casos. Pesq. Vet. Bras. 27(8):325-332.

Inkelmann M.A., Kommers G.D., Fighera R.A., Irigoyen L.F., Barros C.S.L., Silveira I.P. \& Trost M.E. 2011. Neoplasmas do sistema urinário em 113 cães. Pesq. Vet. Bras. 31(12):1102-1107.

Inkelmann M.A., Kommers G.D., Trost M.E., Barros C.S.L., Fighera R.A., Irigoyen L.F. \& Silveira I.P. 2012. Urolitíase em 76 cães. Pesq. Vet. Bras. 32(3):247-253.

Lewis R.J. 1976. Canine glomerulonephritis: Results from a microscopic evaluation of fifty cases Can. Vet. Journal 17(7):171-176.

Lulich J.P., Osborne C.A., Bartges J.W. \& Lekcharoensuk C. 2008. Distúrbios do trato urinário inferior dos caninos, p.1841-1877. In: Ettinger S.J. \& Feldman E.C. (Eds), Tratado de Medicina Interna Veterinária: doenças do cão e do gato. Vol.2. $5^{\mathrm{a}}$ ed. Guanabara Koogan, Rio de Janeiro.

Maxie M.G. \& Newman S.J. 2007. The urinary system, p.425-522. In: Maxie M.G. (Ed.), Jubb, Kennedy, and Palmer's Pathology of Domestic Animals. Vol.2. $5^{\text {th }}$ ed. Saunders Elsevier, Philadelphia.

Meuten D.J. 2002. Tumors of the urinary system, p.509-546. In: Meuten D.J. (Ed.), Tumors in Domestic Animals. $4^{\text {th }}$ ed. Iowa State Press, Ames.

Newman S.J., Anthony W.C. \& Panciera R.J. 2007. Urinary system, p.613691. In: MacGavin M.D. \& Zachary J.F. (Eds), Pathologic Basis of Veterinary Disease. $4^{\text {th }}$ ed. Mosby-Elsevier, St Louis.

Ortega-Pacheco A., Colin-Flores R.F., Gutiérrez-Blanco E. \& Jiménez-Coello M. 2008. Frequency and type of renal lesions in dogs naturally infected with Leptospira species. Anim. Biodiversity Emerg. Dis. Ann. N.Y. Acad. Sci. 1149:270-274.

Osborne C.A., Lulich J.P., Unger L.K., Bartges J.W. \& Felice L.J. 1996. Urolitíase canina e felina: relação da etiopatogenia com o tratamento e prevenção, p.543-596. In: Bojrab M.J. (Ed.), Mecanismos da Moléstia na Cirurgia dos Pequenos Animais. 2a ed. Manole, São Paulo.

Polzin D.J., Osborne C.A., Jacob F. \& Ross S. 2008. Insuficiência renal crônica, p.1721-1751. In: Ettinger S.J. \& Feldman E.C. (Eds), Tratado de Medicina Interna Veterinária: doenças do cão e do gato. Vol.2. 5a ed. Guanabara Koogan, Rio de Janeiro.

Rouse B.T. \& Lewis R.J. 1975. Canine glomerulonephritis: Prevalence in dogs submitted at random for euthanasia. Can. J. Comp. Med. 39:365370.

Sapierzynski R., Malicka E., Bielecki W., Krawiec M., Osinska B., Sendecka H. \& Sobczak-Filipiak M. 2007. Tumors of the urogenital system in dogs and cats: Retrospective review of 138 cases. Pol. J. Vet. Sci. 10(2):97-103.

Schoning P. \& Cowan L.A. 1993. Gross and microscopic lesions of 230 Kansas greyhounds. J. Vet. Diagn. Invest. 5:392-397.

Serakides R. 2010. Sistema urinário, p.291-336. In: Santos R.L. \& Alessi A.C. (Eds), Patologia Veterinária. Roca, São Paulo.

Silva M.C., Fighera R.A., Brum J.S., Graça D.L., Kommers G.D., Irigoyen L.F. \& Barros C.S.L. 2007. Aspectos clinicopatológicos de 620 casos neurológicos de cinomose em cães. Pesq. Vet. Bras. 27(5):215-220.

Sonne L., Oliveira E.C., Pescador C.A., Santos A.S., Pavarini S.P., Carissimi A.S. \& Driemeier D. 2009. Achados patológicos e imuno-histoquímicos em cães infectados naturalmente pelo vírus da cinomose canina. Pesq. Vet. Bras. 29(2):143-149.

Spagnol C., Loretti A.P., Oliveira E.C., Oliveira R.T. \& Driemeier D. 2006. Aspectos epidemiológicos e patológicos da endocardite bacteriana em cães: 54 casos (2000-2005). Acta Scientiae Veterinariae 34(3):255-260.

Trapp S.M., Iacuzio A.I., Barca Junior F.A., Kemper B., Silva L.C., Okano W., Tanaka N.M., Grecco F.C.A.R., Cunha Filho L.F.C. \& Sterza F.A.M. 2010. Causas de óbito e razões para eutanásia em uma população hospitalar de cães e gatos. Braz. J. Vet. Res. Anim. Sci. 47(5):395-402.

Wild C.J., Greenlee J.J., Bolin C.A., Barnett J.K., Haake D.A. \& Cheville N.F. 2002. An improved immunohistochemical diagnostic technique for canine leptospirosis using antileptospiral antibodies on renal tissue. J. Vet. Diagn. Invest. 14:20-24. 